Supporting Information

\title{
Colorimetric Detection of Aliphatic Alcohols in $\beta$-Cyclodextrin Solutions
} Anna Haynes, ${ }^{a}$ Priva Halpert, ${ }^{b}$ Mindy Levine ${ }^{a * l}$

${ }^{a}$ Department of Chemistry, University of Rhode Island, 140 Flagg Road, Kingston, RI 02881

${ }^{b}$ Stella K. Abraham High School for Girls, 291 Meadowview Ave, Hewlett, NY 11557

*Corresponding author: Email: m_levine@uri.edu,mindy.levine@gmail.com; tel; 401-874-4243

${ }^{1}$ Current institutional affiliation is at Ari'el University, 65 Ramat HaGolan Street, Ari'el 


\section{TABLE OF CONTENTS}

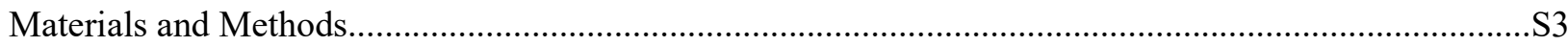

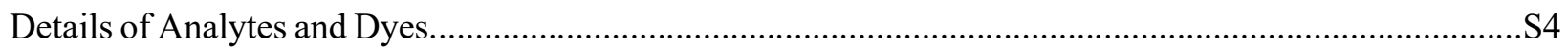

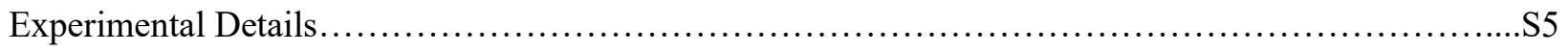

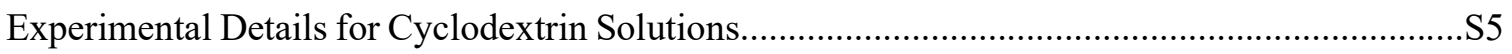

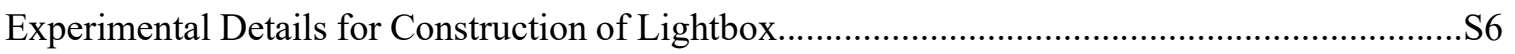

Experimental Details for Cropping Photographs and RGB Measurement....................................S7

Experimental Details for Optimization of the Supramolecular Cyclodextrin Host..........................S8

Experimental Details for Optimization of Analyte Concertation...................................................S9

Experimental Details for Limit of Detection Experiments..........................................................S10

Experimental Details for Binding Constant Experiments.......................................................... 11

Experimental Details for Array Generation............................................................................

Experimental Details for Computational Modeling................................................................S13

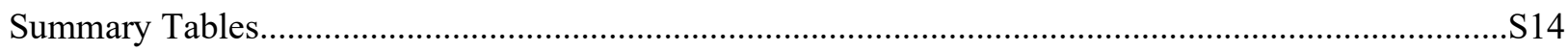

Summary Tables for Optimization of Cyclodextrin Experiments............................S14

Summary Tables for Concentration Optimization Experiments............................S16

Summary Tables for LOD and LOQ Experiments..................................... 19

Summary Tables for Binding Experiments............................................ 20

Summary Tables for Colorimetric Array Experiments...................................S2

Summary Tables for Control Experiments........................................... 23

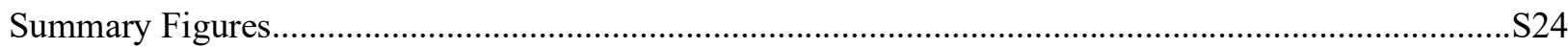

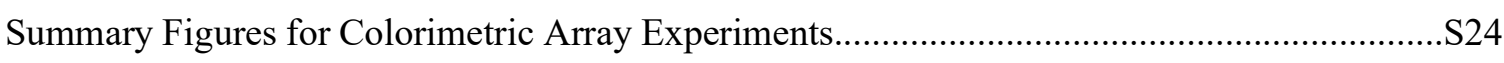

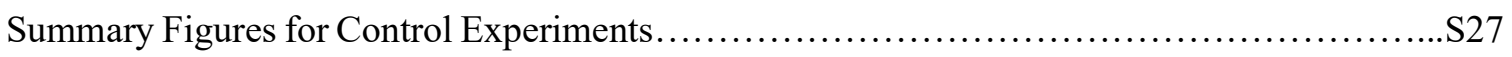

Summary Figures for All LOD Experiments....................................... 28

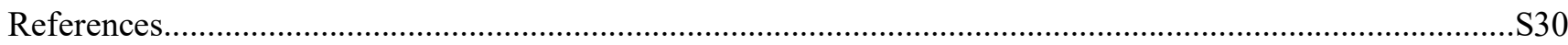




\section{MATERIALS AND METHODS}

The analytes and dyes were obtained from Millipore Sigma chemical company and the cyclodextrins were obtained from Tokyo Chemical Industry chemical company, and all chemicals were used as received. Samples were illuminated using the homemade lightbox detailed on the following page. All photos were taken with a Samsung Galaxy S8+ (model number: G950U) on manual mode with the following settings: ISO set to 100, aperture set to $1 / 350$, macro focused (close-up focus), and the white balance set at $5500 \mathrm{~K}$. Images were cropped using software from https:/www.birme.net. Fluorescence measurements for the binding experiments were performed using a Shimadzu RF 6000 spectrophotometer. Both the excitation and emission slit widths were set to $3.0 \mathrm{~nm}$. All fluorescence spectra were integrated vs. wavenumber on the X-axis using OriginPro 2019 Version 9.60. All arrays were generated using SYSTAT Version 13.1. 


\section{DETAILS OF ANALYTES AND DYES}<smiles>CCOC(C)O</smiles><smiles>[Z]CNc1cc2c(cc1C)C(c1ccccc1C(=O)OCC)=C1C=C(C)C(NCC)=CC1O2</smiles>

Figure S1: Structure of alcohol analytes and highly colored dyes

All analytes were used as received. The dyes were prepared at a concentration of $1.0 \mathrm{mg} / \mathrm{mL}$ in isopropanol. Diluted dye solutions were prepared by diluting $5.0 \mathrm{~mL}$ of the concentrated stock solutions with $150 \mathrm{~mL}$ of DI $\mathrm{H}_{2} \mathrm{O}$. The final concentrations of the dyes are shown in Table $\mathrm{S} 1$, below.

Table S1. Concentration of Dyes in Solution

\begin{tabular}{|l|l|l|}
\hline Dye Number & $\begin{array}{l}\text { Concentration before } \\
\text { Dilution }(\mathbf{m M})\end{array}$ & Final Concentration (mM) \\
\hline $\mathbf{4}$ & 3.796 & 0.1265 \\
\hline $\mathbf{5}$ & 2.079 & 0.0693 \\
\hline
\end{tabular}




\section{EXPERIMENTAL DETAILS FOR CYCLODEXTRIN SOLUTIONS}

The method for making the cyclodextrin solutions was taken from the previous work of high school student Priva Halpert working under the supervision of Dr. Levine. As a high school student working remotely, Halpert based her measurements on volume of each component, using teaspoons, cups, etc. In her procedure, 0.5 teaspoon of cyclodextrin was added to 0.25 cups $(59.15 \mathrm{~mL})$. We wanted to replicate her procedure and converted her measurement of 0.5 teaspoons to grams for each cyclodextrin and scaled up to make a solution with a final volume of $250 \mathrm{~mL}$. These conversions are summarized in the table below, together with the final concentrations of the cyclodextrins.

Table S2. Volume to Mass Conversions of Cyclodextrins and Final Concentrations

\begin{tabular}{|l|l|l|l|}
\hline Cyclodextrin & $\begin{array}{l}\text { Mass of } \mathbf{0 . 5} \\
\text { teaspoons }(\mathbf{g})\end{array}$ & $\begin{array}{l}\text { Mass added to 250 } \mathbf{~ m L} \\
\text { of DI } \mathbf{H}_{\mathbf{2}} \mathbf{O}(\mathbf{g})\end{array}$ & $\begin{array}{l}\text { Final Concentration } \\
(\mathbf{m M})\end{array}$ \\
\hline$\beta$-Cyclodextrin & 1.470 & 4.6806 & 16.49 \\
\hline Methyl- $\beta$-Cyclodextrin & 0.750 & 3.1717 & 9.685 \\
\hline 2-hydroxypropyl- $\beta-C D$ & 0.778 & 3.2852 & 2.389 \\
\hline
\end{tabular}




\section{EXPERIMENTAL DETAILS FOR CONSTRUCTION OF THE LIGHTBOX}

A plastic container (with dimensions $21 \mathrm{~cm}$ x $15 \mathrm{~cm}$ x $7 \mathrm{~cm}$ ) was painted using Krylon Fusion Satin Black spray paint to limit ambient light, and a $1.5 \mathrm{~cm} \times 1.5 \mathrm{~cm}$ hole was cut in the center of the lid to enable photography of the solution. An additional polypropylene cup previously used for a Keurig machine was positioned under the opening after thorough washing, and the cup was secured to the bottom of the container with electrical tape. Two strips of LED white light tape (purchased from The Home Depot; link: https:/www.homedepot.com/p/Commercial-Electric-12-in-30-cm-Linkable-Single-Color-Indoor-LEDFlexible-Tape-Light-Kit-4-Strip-Pack-17066/207018583) were placed on the interior of the container, on all sides, and turned on to provide uniform sample illumination.

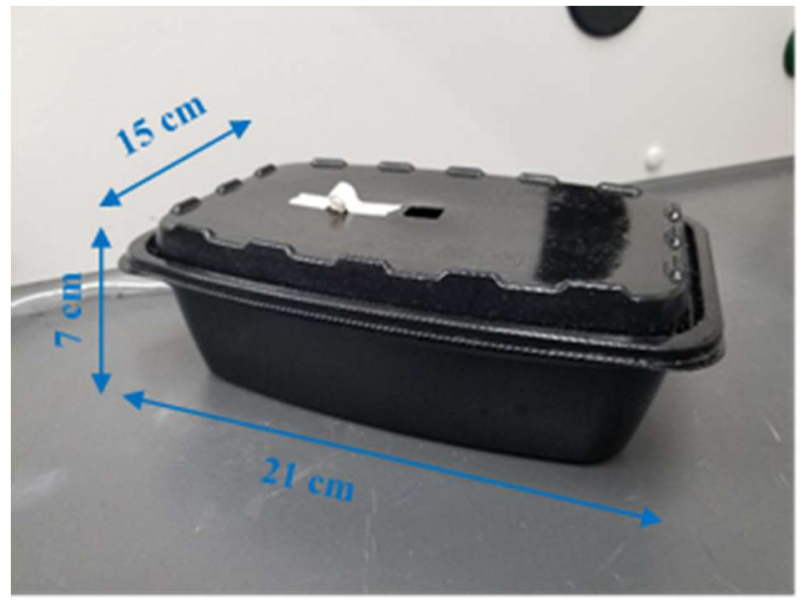

Figure S2. Annotated dimensions of lightbox

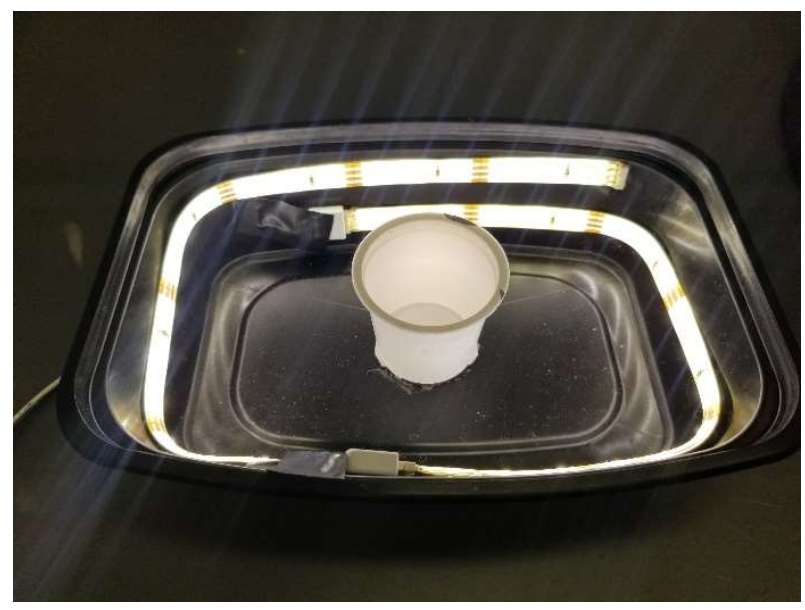

Figure S4. Illuminated lightbox

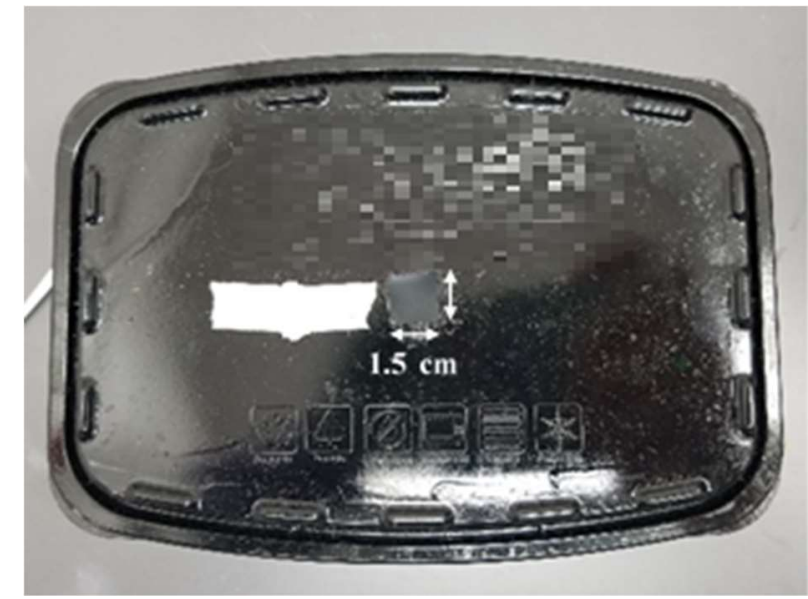

Figure S3. Top view of lightbox

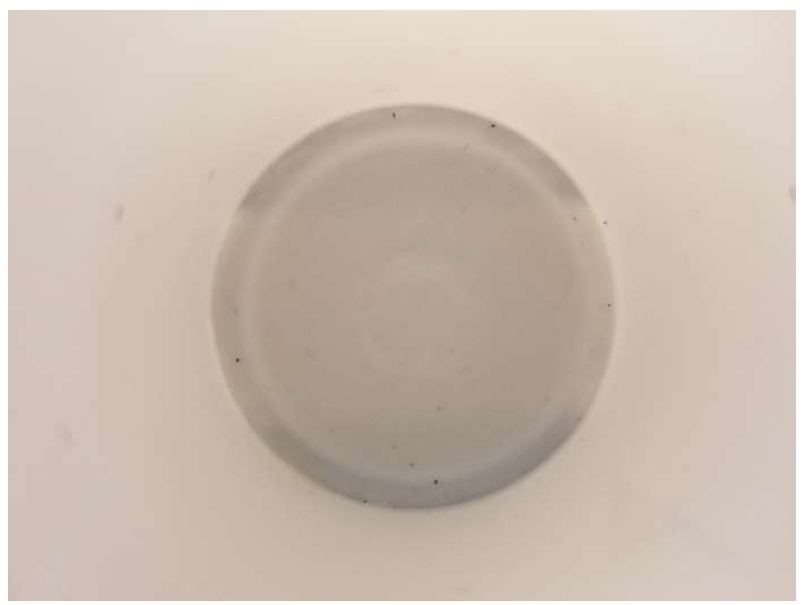

Figure S5. Empty sample cup illuminated 


\section{EXPERIMENTAL DETAILS FOR CROPPING PHOTOGRAPHS AND RGB MEASUREMENTS}

All photographs were cropped using the online tool found at https://www.birme.net. Photos from the same trial were uploaded to the site then cropped to a 500x500 pixel ratio (Figure S6). The cropped photos were then opened into the ImageJ software. These measurements were recorded using the RGB measurement plug-in provided in the software (Figure S7).

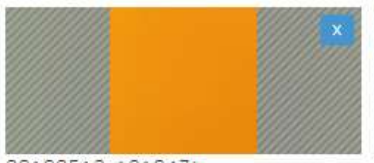

20190513_121647.jpg

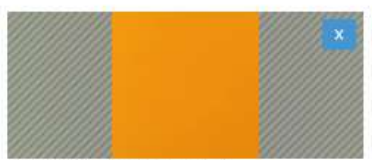

20190513_121718.jpg

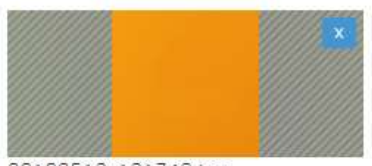

20190513_121743.jpg

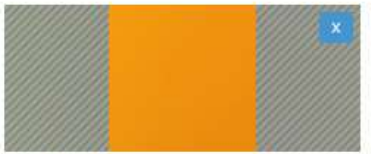

20190513_121934.jpg

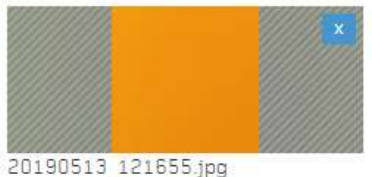

20190513_121655.jpg

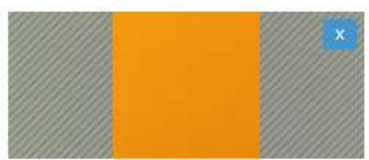

20190513_121723.jpg
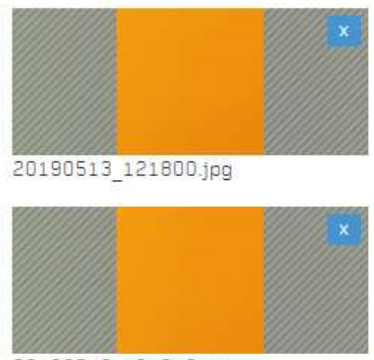

20190513_121940.jpg

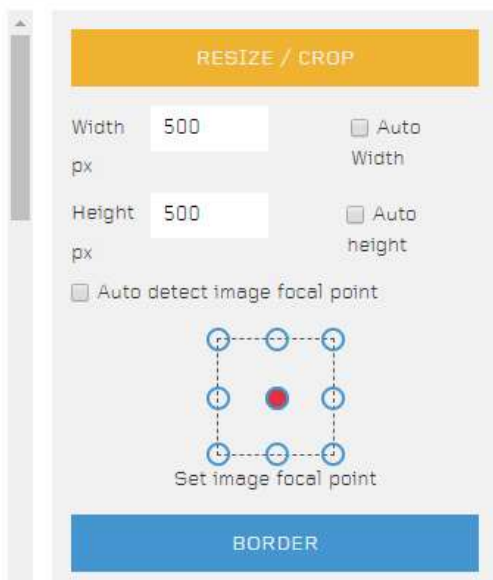

IMAGE FORMAT \& QUALITY

RENAME

SAVE AS ZIP SAVE FILES

Figure S6. Cropping sample photos to 500x500 pixel ratio using software on https://www.birme.net

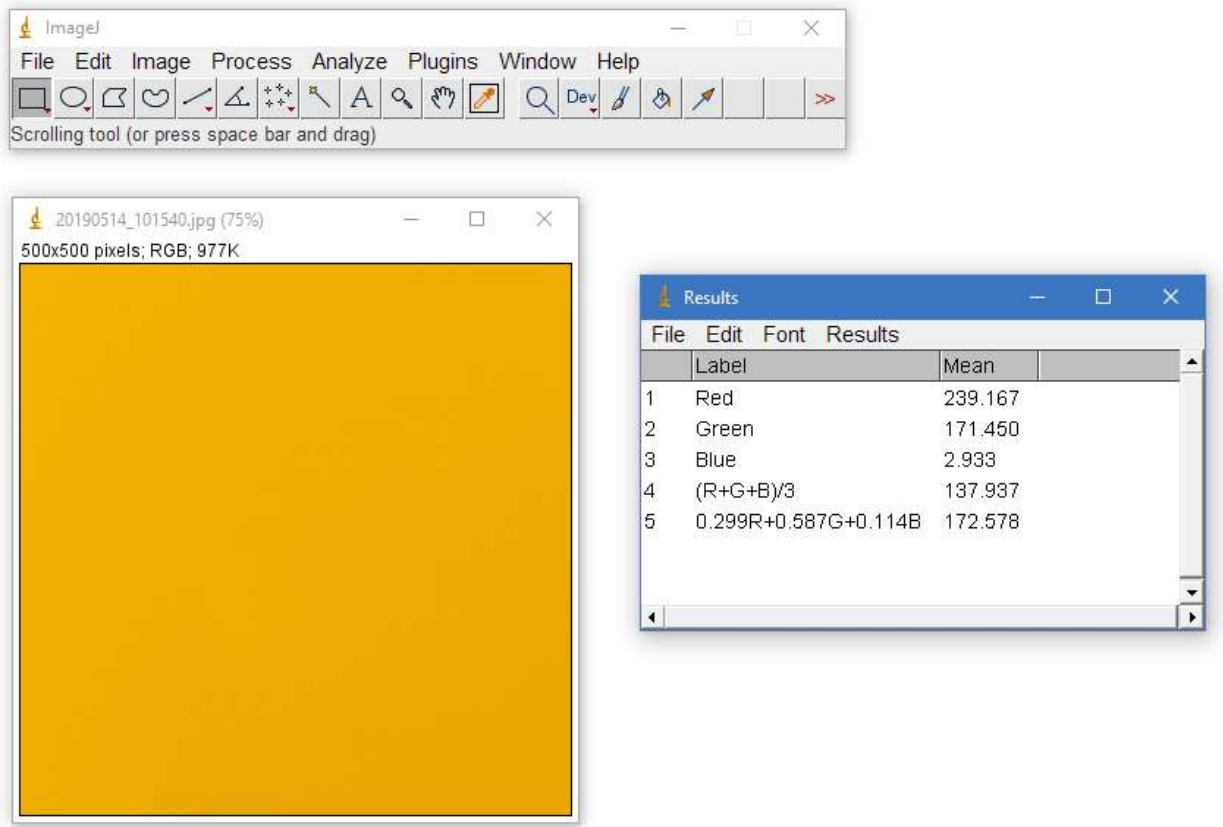

Figure S7. Processing of cropped sample photo using the ImageJ software RGB Measurement plug-in. 


\section{EXPERIMENTAL DETAILS FOR THE OPTIMIZATION OF THE SUPRAMOLECULAR CYCLODEXTRIN HOST}

In a glass sample jar, $10.0 \mathrm{~mL}$ of $\beta$-cyclodextrin stock solution was combined with $10.0 \mathrm{~mL}$ of one of the diluted dye solutions. This mixture was manually shaken for 1 minute to ensure a homogeneous mixture. After mixing, $5.0 \mathrm{~mL}$ of alcohol was added. This mixture was transferred to the sample cup and placed in the lightbox. The cover was placed on and a photo was taken using the smartphone with the settings detailed above. This procedure was repeated for methyl- $\beta$-cyclodextrin and 2-hydroxypropyl- $\beta$-cyclodextrin with both dyes and each of the three alcohols (18 total samples). These samples were replicated 4 times in total with an average standard deviation in RGB values of $0.70 \%$. Full summary tables of standard deviation and standard deviation percentages can be seen on page S15. As a control, experiments were also conducted in the absence of cyclodextrin but under otherwise identical conditions. Summary tables and figures from these experiments are included herein. 


\section{EXPERIMENTAL DETAILS FOR THE OPTIMIZATION OF ANALYTE CONCENTRATION}

In a glass sample jar, $10.0 \mathrm{~mL}$ of 2-hydroxypropyl- $\beta$-cyclodextrin stock solution was combined with 10.0 $\mathrm{mL}$ of one of the diluted dye solutions. This mixture was manually shaken for 1 minute to ensure a homogeneous mixture. A $0.5 \mathrm{M}$ solution of the alcohol was made by adding the corresponding amount of alcohol to the cyclodextrin-dye solution in the glass jar, with additional samples tested for each alcohol at a variety of concentrations $(0.5 \mathrm{M}, 1.0 \mathrm{M}, 2.0 \mathrm{M}$, and $3.0 \mathrm{M})$ using both BODIPY and Rhodamine dyes $(8$ samples replicated 3 times each). The volume of alcohol necessary to obtain an $0.5 \mathrm{M}$ solution is seen in Table S3, below. These solutions were transferred to a sample cup, placed in the lightbox, and a photo was taken of each.

Table S3. Amount of Alcohol Added in Each Solution

\begin{tabular}{|l|l|l|l|l|}
\hline Cyclodextrin & $\mathbf{0 . 5} \mathbf{M}$ & $\mathbf{1 . 0} \mathbf{M}$ & $\mathbf{2 . 0} \mathbf{M}$ & $\mathbf{3 . 0} \mathbf{M}$ \\
\hline Isopropanol & $0.790 \mathrm{~mL}$ & $1.650 \mathrm{~mL}$ & $3.590 \mathrm{~mL}$ & $5.915 \mathrm{~mL}$ \\
\hline Ethanol & $0.600 \mathrm{~mL}$ & $1.240 \mathrm{~mL}$ & $2.640 \mathrm{~mL}$ & $4.240 \mathrm{~mL}$ \\
\hline Methanol & $0.415 \mathrm{~mL}$ & $0.845 \mathrm{~mL}$ & $1.765 \mathrm{~mL}$ & $2.770 \mathrm{~mL}$ \\
\hline
\end{tabular}




\section{EXPERIMENTAL DETAILS FOR LIMIT OF DETECTION EXPERIMENTS}

The limit of detection (LOD), defined as the lowest concentration of the analyte that can be detected, was obtained using the calibration curve method, following procedures reported by Loock et. al. The limit of quantification (LOQ) is the lowest concentration of analyte that can be quantified. The limit of detection ${ }^{1}$ and quantification ${ }^{2}$ experiments were conducted following literature-reported procedures.

To determine the LOD and LOQ, each dye-analyte combination in 2-hydroxypropyl- $\beta$-cyclodextrin solution was examined in the following manner:

1. In a glass sample jar, $10.0 \mathrm{~mL}$ of 2-hydroxypropyl- $\beta$-cyclodextrin stock solution was combined with 10.0 $\mathrm{mL}$ of one of the diluted dye solutions. This mixture was manually shaken for 1 minute to ensure a homogeneous mixture.

2. The solution was transferred to a sample cup and subsequently placed in the light box. A photo was taken in order to obtain the blank measurement of the solution (i.e. in the absence of any alcohol, before any analyte had been added).

3. Using a $20-200 \mu \mathrm{L}$ Fisherbrand Elite micropipette, $100 \mu \mathrm{L}$ of an alcohol was added and a picture was taken. These $100 \mu \mathrm{L}$ additions continued until $6.0 \mathrm{~mL}$ of alcohol was in solution.

4. Steps 1-3 were repeated 3 times for each dye-analyte combination (6 combinations, 18 total samples).

5. Photos were cropped to a 500x500 pixel ratio centered on the center of the sample cup using software from https://www.birme.net and the RGB values of the photos were measured using the RGB measurement plug-in tool in the ImageJ software.

6. The Green values (Y-axis) were chosen to be plotted verses the molarity (X-axis), because they exhibited the most consistent trends. Calibration curves were generated, fitted with an exponential function and an equation was determined.

7. The limit of the blank is defined according to the following equation:

$L O D_{\text {Blank }}=m_{\text {Blank }}+3\left(S D_{\text {Blank }}\right)$,

Equation S1.

where $m$ is the average of the values obtained from the blank sample and $S D$ is the standara deviation of those measurements.

8. The limit of the blank was entered as the $\mathrm{y}$-value in the equation from step 6 , and the corresponding $\mathrm{x}$ value was calculated. This value was the LOD of the system in M.

9. The LOQ was determined in a similar procedure to the LOD. The limit of quantification blank is defined according to the following equation:

$L O Q_{\text {Blank }}=m_{\text {Blank }}+10\left(S D_{\text {Blank }}\right)$.

Equation S2.

This value is then inputted as the y-value in the equation from step 6, and the correspondilis $\Lambda^{-v}$ aruu was calculated. This value is the LOQ for the system in M. 


\section{EXPERIMENTAL DETAILS FOR BINDING CONSTANT EXPERIMENTS}

Fluorescence measurements were performed on a Shimadzu RF 6000 spectrophotometer. Both the excitation and emission slit widths were set to $3.0 \mathrm{~nm}$.

A $1.45 \mathrm{mM}$ solution of 2-HP- $\beta$-CD was prepared in $\mathrm{DI}_{2} \mathrm{O}$. A solution of $2.09 \mathrm{mM}$ dye 5 was prepared in DI $\mathrm{H}_{2} \mathrm{O}$ and a $2.54 \mathrm{mM}$ solution of dye 4 was prepared in tetrahydrofuran, with the solvent selection and concentration optimized based on concentration. In both binding experiments, $2.50 \mathrm{~mL}$ of water was added to quartz cuvette. In the dye 5 trial, $8 \mu \mathrm{L}$ of the dye was added. In the dye 4 series, $10.5 \mu \mathrm{L}$ was added. The tip of the micropipette was used to stir the solution in the cuvette to ensure a homogeneous mixture. Fluorescence measurements of these were taken 4 times. In each trial, $1 \mu \mathrm{L}$ of the 2 -HP- $\beta-\mathrm{CD}$ solution was added to the cuvette and the same scanning process was completed. This was repeated for the total addition amounts seen on page S19 in Tables S10 and S11, the total addition amount representing the concentration at which the observed signal plateaued. All fluorescence spectra were integrated vs. wavenumber on the Xaxis using OriginPro 2019 Version 9.60. Binding constants $\left(\mathrm{K}_{\mathrm{a}}\right)$ were determined using the equation shown below:

$F / F_{0}=1+\left(\left(F / F_{0}\right)_{\max }-1\right)\left(K_{a}[G]_{0} /\left(1+K_{a}[G]_{0}\right)\right.$,

Equation S3.

where $F$ is the fluorescence of the sample, $F_{0}$ is the fluorescence of the blank, $[G]$ is the concentration of the guest which in this case is $2-\mathrm{HP}-\beta-\mathrm{CD}$, and $K_{a}$ is the binding constant. The average $\mathrm{K}_{\mathrm{a}}$ was determined to be $3.32 \times 10^{5} \mathrm{M}^{-1}$ and $1.59 \times 10^{5} \mathrm{M}^{-1}$ for dyes 4 and 5 respectively. 


\section{EXPERIMENTAL DETAILS FOR ARRAY GENERATION EXPERIMENTS}

Array analysis was performed using SYSTAT 13 statistical computing software with the following settings:

(a) Classical Discriminant Analysis

(b) Grouping Variable: Analytes

(c) Predictors: Red, Green, Blue

(d) Long-Range Statistics: Mahal

Arrays were generated for all analyte-dye-cyclodextrin combinations in the optimization experiments.

The results are summarized in the tables, starting on the page S20, and in the figures, beginning on page S22. 


\section{EXPERIMENTAL DETAILS FOR COMPUTATIONAL MODELING}

Spartan '18 was used to calculate the equilibrium at ground state in the gas phase, using a semi-empirical PM3 model for each analyte (Figure S8). This allowed an electrostatic potential map surface to be overlaid on the molecules. Molecular Operating Environment 2018 (MOE) was used to do the docking studies for each dye and 2-HP- $\beta$-CD. A general energy minimization was performed using the "quick prep" function and the default settings. For the docking studies, the set of atoms defined as the receptor was both 2-HP- $\beta$ $\mathrm{CD}$ and the solvent so that the dye could move freely in the system. Placement was done using the Triangle Matches method with London Dispersion dG score in 30 poses. Refinement was done using the Rigid Receptor method with GBVI/WSA dG score in 5 poses (Figure S9). This generated the docking of the dyecyclodextrin complex with the lowest energy confirmation.

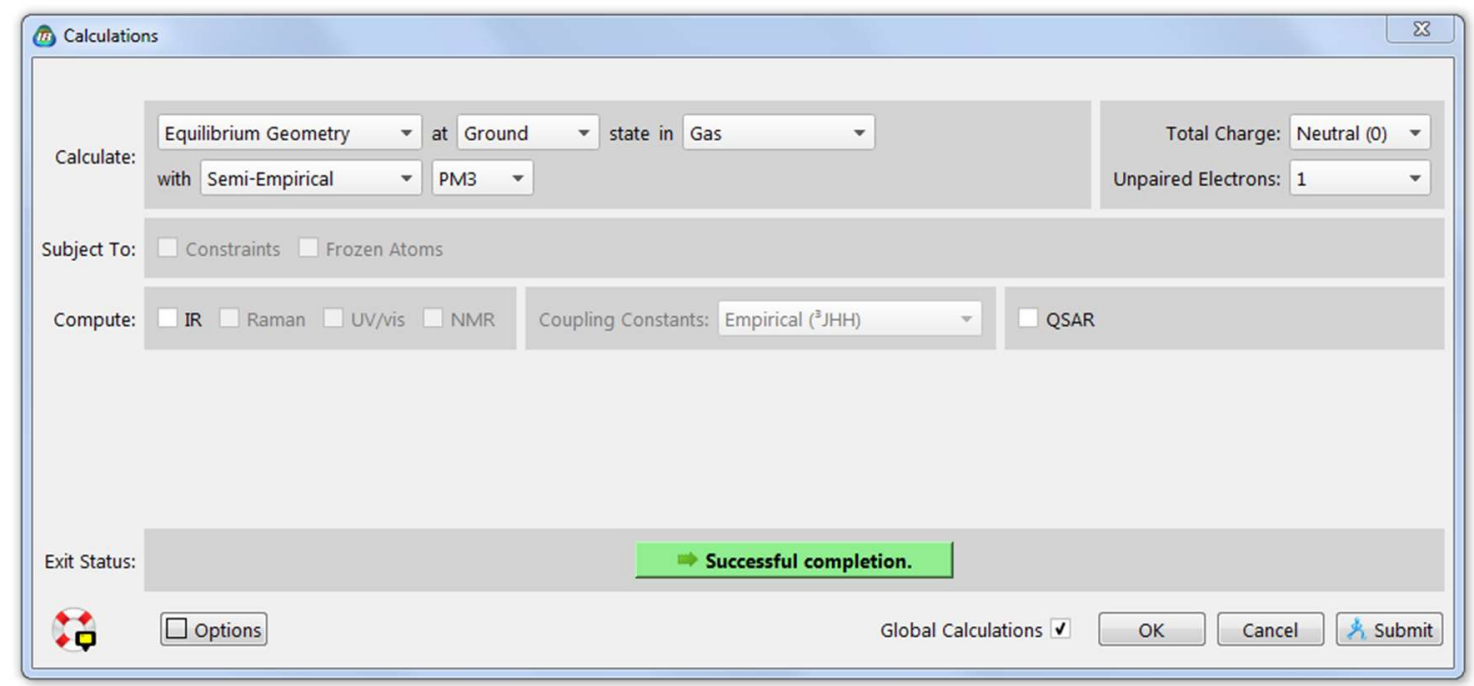

Figure S8. Spartan '18 dialogue box with the settings used for calculation of equilibrium geometry.

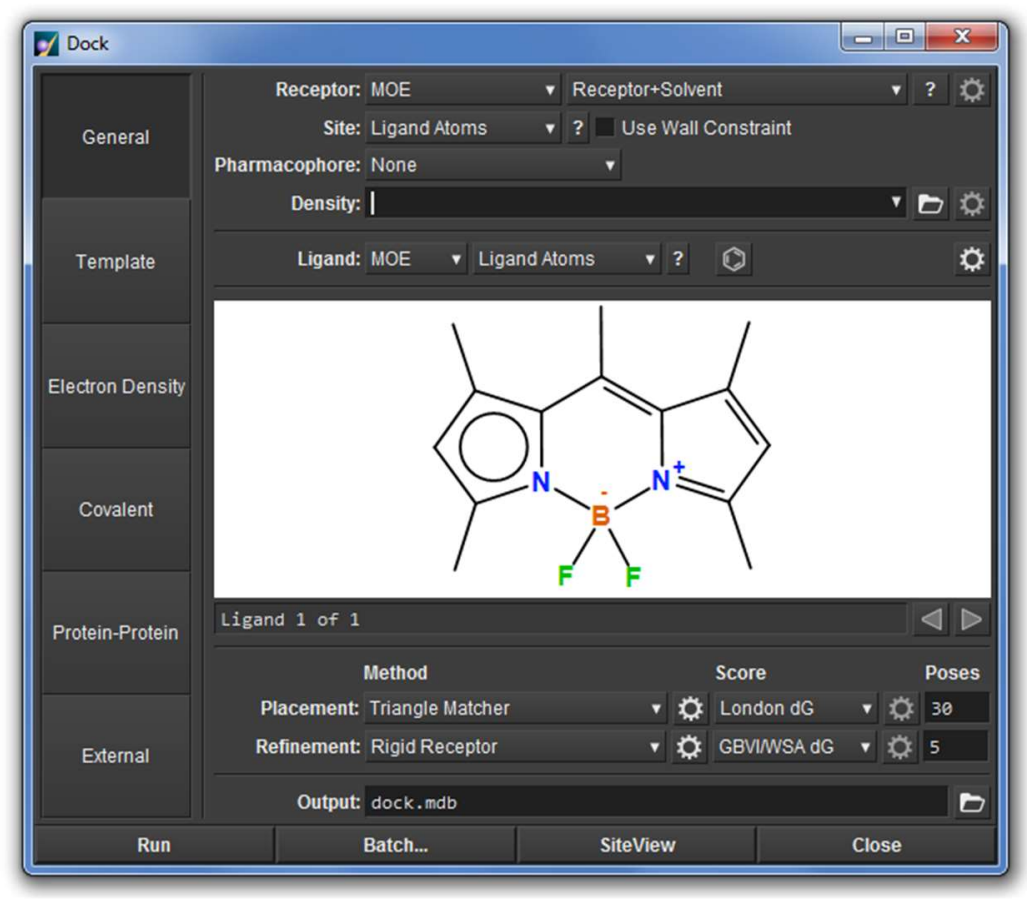

Figure S9. MOE 2018 dialogue box with the settings used for the docking calculations. 
SUMMARY TABLES FOR OPTIMIZATION OF CYCLODEXTRIN EXPERIEMNTS

Table S4. RGB Measures of Cyclodextrin-Analyte Combinations with Dyes 4 and 5

\begin{tabular}{|c|c|c|c|c|c|c|c|}
\hline \multirow{2}{*}{\begin{tabular}{|l|} 
Cyclodextrin \\
\end{tabular}} & \multirow{2}{*}{ Analyte } & \multicolumn{3}{|l|}{ Dye 4} & \multicolumn{3}{|l|}{ Dye 5} \\
\hline & & Red & Green & Blue & Red & Green & Blue \\
\hline \multirow{12}{*}{$\beta-C D$} & \multirow{4}{*}{ Isopropanol } & 229.326 & 162.309 & 2.674 & 248.446 & 125.19 & 1.782 \\
\hline & & 229.686 & 162.166 & 2.711 & 248.196 & 125.264 & 1.796 \\
\hline & & 229.522 & 162.683 & 2.708 & 248.35 & 125.206 & 1.791 \\
\hline & & 229.631 & 161.993 & 2.696 & 248.282 & 125.225 & 1.792 \\
\hline & \multirow{4}{*}{ Ethanol } & 228.556 & 164.062 & 3.058 & 245.065 & 125.688 & 1.8 \\
\hline & & 228.86 & 163.756 & 3.086 & 244.803 & 125.694 & 1.851 \\
\hline & & 228.839 & 164.402 & 2.95 & 244.971 & 125.699 & 1.808 \\
\hline & & 228.928 & 163.684 & 2.902 & 244.848 & 125.665 & 1.834 \\
\hline & \multirow{4}{*}{ Methanol } & 228.012 & 162.721 & 2.156 & 246.063 & 126.866 & 1.569 \\
\hline & & 228.335 & 162.413 & 2.136 & 245.885 & 126.996 & 1.788 \\
\hline & & 228.145 & 162.91 & 2.119 & 246.043 & 126.965 & 1.625 \\
\hline & & 228.218 & 162.214 & 2.182 & 245.953 & 126.986 & 1.729 \\
\hline \multirow{12}{*}{ M- $\beta-C D$} & \multirow{4}{*}{ Isopropanol } & 229.38 & 159.869 & 2.965 & 248.249 & 125.159 & 3.753 \\
\hline & & 229.672 & 159.58 & 2.986 & 248.513 & 124.875 & 3.746 \\
\hline & & 229.307 & 159.911 & 2.972 & 248.176 & 125.165 & 3.736 \\
\hline & & 229.49 & 159.772 & 2.983 & 248.353 & 124.985 & 3.717 \\
\hline & \multirow{4}{*}{ Ethanol } & 229.054 & 159.4 & 2.789 & 247.118 & 124.484 & 4.095 \\
\hline & & 229.35 & 159.669 & 2.846 & 247.392 & 123.999 & 4.05 \\
\hline & & 229.012 & 158.958 & 2.826 & 247.011 & 124.875 & 4.086 \\
\hline & & 229.109 & 159.563 & 2.771 & 247.155 & 124.981 & 4.09 \\
\hline & \multirow{4}{*}{ Methanol } & 229.02 & 159.398 & 2.81 & 248.061 & 124.455 & 3.459 \\
\hline & & 229.946 & 159.065 & 2.559 & 248.378 & 124.153 & 3.405 \\
\hline & & 228.449 & 159.348 & 2.787 & 247.963 & 124.484 & 3.614 \\
\hline & & 229.372 & 159.128 & 3.001 & 248.14 & 124.334 & 3.573 \\
\hline \multirow{6}{*}{$2-\mathrm{HP}-\beta-\mathrm{CD}$} & \multirow{4}{*}{ Isopropanol } & 236.315 & 185.085 & 4.147 & 258.453 & 165.344 & 2.221 \\
\hline & & 236.88 & 185.564 & 4.111 & 257.953 & 164.814 & 2.176 \\
\hline & & 236.55 & 185.294 & 4.103 & 258.259 & 165.094 & 2.182 \\
\hline & & 236.641 & 185.368 & 4.129 & 258.174 & 165.003 & 2.184 \\
\hline & \multirow{2}{*}{ Ethanol } & 233.448 & 158.496 & 3.736 & 259.583 & 167.58 & 2.677 \\
\hline & & 233.62 & 158.678 & 3.735 & 259.392 & 167.38 & 2.599 \\
\hline
\end{tabular}




\begin{tabular}{|l|l|l|l|l|l|l|l|}
\hline & 233.931 & 158.977 & 3.676 & 259.093 & 167.151 & 2.604 \\
\cline { 3 - 8 } & 234.134 & 159.18 & 3.704 & 258.895 & 167.015 & 2.654 \\
\cline { 2 - 8 } & \multirow{4}{*}{ Methanol } & 238.767 & 155.928 & 3.401 & 257.994 & 160.909 & 2.843 \\
\cline { 2 - 8 } & 238.893 & 156.037 & 3.379 & 257.877 & 160.841 & 2.961 \\
\cline { 2 - 8 } & 238.56 & 155.729 & 3.384 & 258.159 & 161.11 & 2.372 \\
\cline { 2 - 8 } & 238.496 & 155.653 & 3.365 & 258.098 & 161.219 & 3.22 \\
\hline
\end{tabular}

Table S5. Standard Deviations of RGB Measures of All Cyclodextrin-Analyte Combinations with Dyes 4 and 5

\begin{tabular}{|c|c|c|c|c|c|c|c|}
\hline \multirow[b]{2}{*}{ Cyclodextrin } & \multirow[b]{2}{*}{ Analyte } & \multicolumn{3}{|l|}{ Dye 4} & \multicolumn{3}{|l|}{ Dye 5} \\
\hline & & Red & Green & Blue & Red & Green & Blue \\
\hline \multirow{3}{*}{$\beta-C D$} & Isopropanol & 0.1589 & 0.2935 & 0.0168 & 0.1058 & 0.0319 & 0.0059 \\
\hline & Ethanol & 0.1643 & 0.3279 & 0.0873 & 0.1190 & 0.0150 & 0.0235 \\
\hline & Methanol & 0.1353 & 0.3107 & 0.0271 & 0.0826 & 0.0596 & 0.0990 \\
\hline \multirow{3}{*}{ Me- $\beta$-CD } & Isopropanol & 0.1588 & 0.1473 & 0.0097 & 0.1462 & 0.1413 & 0.0156 \\
\hline & Ethanol & 0.1511 & 0.3132 & 0.0341 & 0.1607 & 0.4452 & 0.0205 \\
\hline & Methanol & 0.6278 & 0.1630 & 0.1810 & 0.1771 & 0.1504 & 0.0973 \\
\hline \multirow{3}{*}{$2-H P-\beta-C D$} & Isopropanol & 0.2336 & 0.1979 & 0.0196 & 0.2072 & 0.2202 & 0.0205 \\
\hline & Ethanol & 0.3076 & 0.3048 & 0.0287 & 0.3063 & 0.2496 & 0.0382 \\
\hline & Methanol & 0.1837 & 0.1768 & 0.0149 & 0.1238 & 0.1752 & 0.2407 \\
\hline
\end{tabular}

Table S6. Percent Standard Deviations of RGB Measures of Cyclodextrin-Analyte Combinations with Dyes 4 and 5

\begin{tabular}{|c|c|c|c|c|c|c|c|}
\hline \multirow[b]{2}{*}{ Cyclodextrin } & \multirow[b]{2}{*}{ Analyte } & \multicolumn{3}{|l|}{ Dye 4} & \multicolumn{3}{|l|}{ Dye 5} \\
\hline & & Red & Green & Blue & Red & Green & Blue \\
\hline \multirow{3}{*}{$\beta-C D$} & Isopropanol & $0.069 \%$ & $0.181 \%$ & $0.623 \%$ & $0.043 \%$ & $0.025 \%$ & $0.330 \%$ \\
\hline & Ethanol & $0.072 \%$ & $0.200 \%$ & $2.911 \%$ & $0.049 \%$ & $0.012 \%$ & $1.290 \%$ \\
\hline & Methanol & $0.059 \%$ & $0.191 \%$ & $1.262 \%$ & $0.034 \%$ & $0.047 \%$ & $5.900 \%$ \\
\hline \multirow{3}{*}{ Me- $\beta$-CD } & Isopropanol & $0.069 \%$ & $0.092 \%$ & $0.327 \%$ & $0.059 \%$ & $0.113 \%$ & $0.418 \%$ \\
\hline & Ethanol & $0.066 \%$ & $0.196 \%$ & $1.216 \%$ & $0.065 \%$ & $0.357 \%$ & $0.502 \%$ \\
\hline & Methanol & $0.274 \%$ & $0.102 \%$ & $6.489 \%$ & $0.071 \%$ & $0.121 \%$ & $2.769 \%$ \\
\hline \multirow{3}{*}{ 2-HP- $\beta-C D$} & Isopropanol & $0.099 \%$ & $0.107 \%$ & $0.476 \%$ & $0.080 \%$ & $0.133 \%$ & $0.934 \%$ \\
\hline & Ethanol & $0.132 \%$ & $0.192 \%$ & $0.772 \%$ & $0.118 \%$ & $0.149 \%$ & $1.450 \%$ \\
\hline & Methanol & $0.077 \%$ & $0.113 \%$ & $0.439 \%$ & $0.048 \%$ & $0.109 \%$ & $7.766 \%$ \\
\hline
\end{tabular}




\section{SUMMARY TABLES FOR CONCENTRATION OPTIMIZATION EXPERIEMNTS}

Table S7. RGB Measures of Varying Concentrations of Analyte in 2-HP- $\beta$-CD Solution with Dyes 4 and 5

\begin{tabular}{|c|c|c|c|c|c|c|c|}
\hline & & Dye 4 & & & Dye 5 & & \\
\hline Analyte & Concentration & Red & Green & Blue & Red & Green & Blue \\
\hline \multirow{12}{*}{ Isopropanol } & \multirow{3}{*}{$0.5(\mathrm{M})$} & 238.111 & 147.305 & 2.193 & 254.733 & 156.79 & 1.866 \\
\hline & & 238.416 & 146.03 & 2.177 & 254.733 & 156.705 & 1.839 \\
\hline & & 238.381 & 145.778 & 2.097 & 254.706 & 156.172 & 1.781 \\
\hline & \multirow{3}{*}{$1.0(\mathrm{M})$} & 238.845 & 150.321 & 2.277 & 254.754 & 159.842 & 2.522 \\
\hline & & 239.22 & 148.409 & 2.258 & 254.769 & 159.741 & 2.529 \\
\hline & & 239.194 & 148.797 & 2.261 & 254.773 & 158.386 & 2.243 \\
\hline & \multirow{3}{*}{$2.0(\mathrm{M})$} & 238.872 & 164.365 & 2.656 & 254.667 & 164.322 & 2.479 \\
\hline & & 240.322 & 159.668 & 2.625 & 254.666 & 164.221 & 2.542 \\
\hline & & 239.51 & 156.642 & 2.554 & 254.683 & 163.836 & 2.64 \\
\hline & \multirow{3}{*}{$3.0(\mathrm{M})$} & 235.774 & 184.183 & 3.744 & 254.65 & 164.844 & 2.401 \\
\hline & & 237.338 & 187.3 & 3.54 & 254.662 & 164.798 & 2.418 \\
\hline & & 236.972 & 181.636 & 3.29 & 254.65 & 164.483 & 2.443 \\
\hline \multirow{12}{*}{ Ethanol } & \multirow{3}{*}{$0.5(\mathrm{M})$} & 238.143 & 146.809 & 2.198 & 254.725 & 156.132 & 1.76 \\
\hline & & 237.959 & 146.661 & 2.206 & 254.735 & 156.577 & 1.885 \\
\hline & & 238.281 & 148.452 & 2.257 & 254.682 & 154.636 & 1.694 \\
\hline & \multirow{3}{*}{$1.0(\mathrm{M})$} & 238.783 & 148.084 & 2.215 & 254.752 & 157.888 & 2.139 \\
\hline & & 238.571 & 147.951 & 2.262 & 254.762 & 158.104 & 2.21 \\
\hline & & 239.398 & 150.663 & 2.331 & 254.738 & 157.438 & 2.098 \\
\hline & \multirow{3}{*}{$2.0(\mathrm{M})$} & 239.414 & 152.039 & 2.434 & 254.718 & 161.873 & 2.658 \\
\hline & & 238.579 & 150.438 & 2.327 & 254.7 & 162.154 & 2.702 \\
\hline & & 239.706 & 153.549 & 2.493 & 254.714 & 162.028 & 2.555 \\
\hline & \multirow{3}{*}{$3.0(\mathrm{M})$} & 239.551 & 157.139 & 2.594 & 254.656 & 164.283 & 2.502 \\
\hline & & 238.263 & 157.975 & 2.623 & 254.667 & 164.842 & 2.409 \\
\hline & & 239.108 & 159.737 & 2.593 & 254.693 & 164.471 & 2.493 \\
\hline \multirow{5}{*}{ Methanol } & \multirow{3}{*}{$0.5(\mathrm{M})$} & 238.6 & 148.121 & 2.255 & 254.625 & 154.415 & 1.642 \\
\hline & & 240.228 & 149.071 & 2.255 & 254.662 & 154.439 & 1.688 \\
\hline & & 240.219 & 148.381 & 2.263 & 254.666 & 154.457 & 1.713 \\
\hline & \multirow{2}{*}{$1.0(\mathrm{M})$} & 238.891 & 149.142 & 2.281 & 254.727 & 156.382 & 1.829 \\
\hline & & 240.041 & 148.84 & 2.236 & 254.7 & 155.996 & 1.801 \\
\hline
\end{tabular}




\begin{tabular}{|l|l|l|l|l|l|l|l|}
\hline & 240.045 & 148.386 & 2.246 & 254.704 & 155.403 & 1.85 \\
\cline { 2 - 8 } & \multirow{3}{*}{$2.0(\mathrm{M})$} & 239.694 & 152.425 & 2.403 & 254.751 & 159.123 & 2.361 \\
\cline { 3 - 8 } & 240.747 & 151.426 & 2.355 & 254.753 & 158.592 & 2.332 \\
\cline { 2 - 8 } & 240.915 & 150.847 & 2.356 & 254.758 & 158.342 & 2.218 \\
\cline { 2 - 8 } & $3.0(\mathrm{M})$ & 239.049 & 154.9 & 2.53 & 254.711 & 161.973 & 2.679 \\
\cline { 2 - 8 } & 240.847 & 154.191 & 2.51 & 254.726 & 161.574 & 2.642 \\
\cline { 2 - 8 } & 241.502 & 153.745 & 2.5 & 254.708 & 162.272 & 2.586 \\
\hline
\end{tabular}

Table S8. Standard Deviations of RGB Measures of Varying Concentrations of Analyte in 2-HP- $\beta$-CD Solution with Dyes 4 and 5

\begin{tabular}{|c|c|c|c|c|c|c|c|}
\hline & & Dye 4 & & & Dye 5 & & \\
\hline Analyte & Concentration & Red & Green & Blue & Red & Green & Blue \\
\hline \multirow{4}{*}{ Isopropanol } & $0.5(\mathrm{M})$ & 0.1669 & 0.8186 & 0.0514 & 0.0156 & 0.3350 & 0.0434 \\
\hline & $1.0(\mathrm{M})$ & 0.2094 & 1.0107 & 0.0102 & 0.0100 & 0.8130 & 0.0047 \\
\hline & $2.0(\mathrm{M})$ & 0.7267 & 3.8915 & 0.0523 & 0.0095 & 0.2565 & 0.0811 \\
\hline & $3.0(\mathrm{M})$ & 0.8181 & 2.8368 & 0.2274 & 0.0069 & 0.1965 & 0.0211 \\
\hline \multirow{4}{*}{ Ethanol } & $0.5(\mathrm{M})$ & 0.1615 & 0.9941 & 0.0320 & 0.0282 & 1.0168 & 0.0970 \\
\hline & $1.0(\mathrm{M})$ & 0.4296 & 1.5288 & 0.0583 & 0.0121 & 0.3398 & 0.0567 \\
\hline & $2.0(\mathrm{M})$ & 0.5849 & 1.5557 & 0.0841 & 0.0095 & 0.1407 & 0.0754 \\
\hline & $3.0(\mathrm{M})$ & 0.6544 & 1.3262 & 0.0170 & 0.0190 & 0.2844 & 0.0513 \\
\hline \multirow{4}{*}{ Methanol } & $0.5(\mathrm{M})$ & 0.9373 & 0.4910 & 0.0046 & 0.0226 & 0.0211 & 0.0360 \\
\hline & $1.0(\mathrm{M})$ & 0.6651 & 0.3805 & 0.0236 & 0.0146 & 0.4931 & 0.0246 \\
\hline & $2.0(\mathrm{M})$ & 0.6618 & 0.7983 & 0.0274 & 0.0036 & 0.3988 & 0.0756 \\
\hline & $3.0(\mathrm{M})$ & 1.2701 & 0.5825 & 0.0153 & 0.0096 & 0.3502 & 0.0468 \\
\hline
\end{tabular}

Table S9. Percent Standard Deviations of RGB Measures of Varying Concentrations of Analyte in 2-HP$\beta$-CD with Dyes 4 and 5

\begin{tabular}{|l|l|l|l|l|l|l|l|}
\hline & \multicolumn{5}{|c|}{ Dye 4 } & \multicolumn{2}{l|}{ Dye 5 } \\
\hline Analyte & Concentration & Red & Green & Blue & Red & Green & Blue \\
\hline \multirow{3}{*}{ Isopropanol } & $0.5(\mathrm{M})$ & $0.070 \%$ & $0.559 \%$ & $2.386 \%$ & $0.006 \%$ & $0.214 \%$ & $2.375 \%$ \\
\cline { 2 - 8 } & $1.0(\mathrm{M})$ & $0.088 \%$ & $0.678 \%$ & $0.451 \%$ & $0.004 \%$ & $0.510 \%$ & $0.187 \%$ \\
\cline { 2 - 8 } & $2.0(\mathrm{M})$ & $0.303 \%$ & $2.429 \%$ & $2.002 \%$ & $0.004 \%$ & $0.156 \%$ & $3.177 \%$ \\
\cline { 2 - 8 } & $3.0(\mathrm{M})$ & $0.346 \%$ & $1.539 \%$ & $6.451 \%$ & $0.003 \%$ & $0.119 \%$ & $0.873 \%$ \\
\hline \multirow{3}{*}{ Ethanol } & $0.5(\mathrm{M})$ & $0.068 \%$ & $0.675 \%$ & $1.441 \%$ & $0.011 \%$ & $0.653 \%$ & $5.451 \%$ \\
\cline { 2 - 8 } & $1.0(\mathrm{M})$ & $0.180 \%$ & $1.027 \%$ & $2.571 \%$ & $0.005 \%$ & $0.215 \%$ & $2.637 \%$ \\
\hline
\end{tabular}




\begin{tabular}{|l|l|l|l|l|l|l|l|}
\hline & $2.0(\mathrm{M})$ & $0.244 \%$ & $1.023 \%$ & $3.480 \%$ & $0.004 \%$ & $0.087 \%$ & $2.860 \%$ \\
\cline { 2 - 8 } & $3.0(\mathrm{M})$ & $0.274 \%$ & $0.838 \%$ & $0.655 \%$ & $0.007 \%$ & $0.173 \%$ & $2.078 \%$ \\
\hline \multirow{3}{*}{ Methanol } & $0.5(\mathrm{M})$ & $0.391 \%$ & $0.331 \%$ & $0.205 \%$ & $0.009 \%$ & $0.014 \%$ & $2.142 \%$ \\
\cline { 2 - 8 } & $1.0(\mathrm{M})$ & $0.278 \%$ & $0.256 \%$ & $1.048 \%$ & $0.006 \%$ & $0.316 \%$ & $1.346 \%$ \\
\cline { 2 - 8 } & $2.0(\mathrm{M})$ & $0.275 \%$ & $0.527 \%$ & $1.157 \%$ & $0.001 \%$ & $0.251 \%$ & $3.281 \%$ \\
\cline { 2 - 8 } & $3.0(\mathrm{M})$ & $0.528 \%$ & $0.378 \%$ & $0.608 \%$ & $0.004 \%$ & $0.216 \%$ & $1.776 \%$ \\
\hline
\end{tabular}




\section{SUMMARY TABLES OF LOD AND LOQ EXPERIMENTS}

Table S10. Table of LODs and LOQs of Each Alcohol with Dyes 4 and $\mathbf{5}$ in the Presence of 2-HP- $\beta-C D$

\begin{tabular}{|l|l|l|l|l|l|}
\hline Dye & Analyte & LOD (M) & LOQ (M) & Equation & $\mathbf{R}^{\mathbf{2}}$ \\
\hline \multirow{3}{*}{ Dye 4 } & Isopropanol & 0.3187 & 0.8053 & $\mathrm{y}=3.304 \mathrm{e}^{\mathrm{x} / 1.163}+141.606$ & 0.9994 \\
\cline { 2 - 6 } & Ethanol & 0.4911 & 1.7387 & $\mathrm{y}=1.531 \mathrm{e}^{\mathrm{x} / 1.351}+145.250$ & 0.9973 \\
\cline { 2 - 6 } & Methanol & 0.2492 & 0.8235 & $\mathrm{y}=8.048 \mathrm{e}^{\mathrm{x} / 4.913}+139.175$ & 0.9986 \\
\hline \multirow{3}{*}{ Dye 5 } & Isopropanol & 0.3856 & 1.0539 & $\mathrm{y}=-14.641 \mathrm{e}^{\mathrm{x} / 1.665}+167.917$ & 0.9799 \\
\cline { 2 - 6 } & Ethanol & 0.2163 & 0.4416 & $\mathrm{y}=-21.511 \mathrm{e}^{\mathrm{x} / 4.405}+175.206$ & 0.9935 \\
\cline { 2 - 6 } & Methanol & 0.331 & 0.7304 & $\mathrm{y}=-26.284 \mathrm{e}^{\mathrm{x} /-7.820}+179.275$ & 0.9964 \\
\hline
\end{tabular}




\section{SUMMARY TABLES FOR BINDING EXPERIMENTS}

$2-H P-\beta-C D$ was added into the cuvette with the dye solution. Sequential additions were conducted, and were stopped when the fluorescence measurements begin to plateau. Full experimental details can be seen on page S11, above.

Table S11. Additions and Concentrations for Binding of Dye 4 in 2-HP- $\beta-C D$

\begin{tabular}{|l|l|l|}
\hline $\begin{array}{l}\text { Volume of } \\
\text { 2-HP- } \beta-C D \\
\text { added }(\boldsymbol{\mu L})\end{array}$ & $\begin{array}{l}{[\mathbf{2 - H P - \beta - C D ]}} \\
(\boldsymbol{\mu M})\end{array}$ & $\begin{array}{l}{[\mathbf{D y e}} \\
(\boldsymbol{\mu M})\end{array}$ \\
\hline 0 & 0.0000 & 6.383 \\
\hline 1 & 0.5790 & 6.380 \\
\hline 2 & 1.158 & 6.378 \\
\hline 3 & 1.736 & 6.375 \\
\hline 4 & 2.313 & 6.373 \\
\hline 5 & 2.890 & 6.370 \\
\hline 6 & 3.467 & 6.368 \\
\hline 7 & 4.043 & 6.365 \\
\hline 8 & 4.619 & 6.362 \\
\hline 12 & 6.918 & 6.352 \\
\hline 16 & 9.209 & 6.342 \\
\hline 20 & 11.49 & 6.332 \\
\hline 24 & 13.77 & 6.322 \\
\hline 28 & 16.04 & 6.312 \\
\hline
\end{tabular}

Table S12. Additions and Concentrations for Binding of Dye 5 in 2-HP- $\beta-C D$

\begin{tabular}{|c|c|c|}
\hline $\begin{array}{l}\text { Volume of } \\
2-H P-\beta-C D \\
\text { added }(\mu L)\end{array}$ & $\begin{array}{l}{[2-H P-\beta-C D]} \\
(\mu \mathrm{M})\end{array}$ & $\begin{array}{ll}{\left[\begin{array}{ll}\text { Dye } & 5\end{array}\right]} \\
(\boldsymbol{\mu M})\end{array}$ \\
\hline 0 & 0.0000 & 6.659 \\
\hline 1 & 0.5790 & 6.656 \\
\hline 2 & 1.158 & 6.654 \\
\hline 3 & 1.736 & 6.651 \\
\hline 4 & 2.313 & 6.648 \\
\hline 5 & 2.890 & 6.646 \\
\hline 6 & 3.467 & 6.643 \\
\hline 7 & 4.043 & 6.640 \\
\hline 8 & 4.619 & 6.638 \\
\hline 12 & 6.918 & 6.627 \\
\hline 16 & 9.209 & 6.617 \\
\hline 20 & 11.49 & 6.606 \\
\hline 24 & 13.77 & 6.596 \\
\hline 28 & 16.04 & 6.585 \\
\hline 32 & 18.32 & 6.575 \\
\hline 36 & 20.58 & 6.565 \\
\hline 40 & 22.83 & 6.554 \\
\hline
\end{tabular}




\section{SUMMARY TABLES OF COLORIMETRIC ARRAY EXPERIMENTS}

\section{Summary Tables of Cyclodextrin-Analyte Combinations with Dyes 4 and 5 Arrays}

Table S13. Analytes with $\beta-C D$ and Dye 4

Jackknifed Classification Matrix
\begin{tabular}{|l|r|r|r|r|}
\hline & Ethanol & Isopropanol & Methanol & $\%$ correct \\
\hline Ethanol & 4 & 0 & 0 & 100 \\
\hline Isopropanol & 0 & 4 & 0 & 100 \\
\hline Methanol & 0 & 0 & 4 & 100 \\
\hline Total & 4 & 4 & 4 & 100 \\
\hline
\end{tabular}

Cumulative Proportion of Total Dispersion

\begin{tabular}{r|r|}
0.915 & 1.000 \\
\hline
\end{tabular}

Table S14. Analytes with Me- $\beta-C D$ and Dye 4

Jackknifed Classification Matrix

\begin{tabular}{|l|r|r|r|r|}
\hline & Ethanol & Isopropanol & Methanol & \%correct \\
\hline Ethanol & 2 & 1 & 1 & 50 \\
\hline Isopropanol & 0 & 4 & 0 & 100 \\
\hline Methanol & 3 & 1 & 0 & 0 \\
\hline Total & 5 & 6 & 1 & 50 \\
\hline
\end{tabular}

Cumulative Proportion of Total Dispersion

\begin{tabular}{l|l|}
0.986 & 1.000 \\
\hline
\end{tabular}

Table S15. Analytes with 2-HP- $\beta-C D$ and Dye 4

Jackknifed Classification Matrix

\begin{tabular}{|l|r|r|r|r|}
\hline & Ethanol & Isopropanol & Methanol & \%correct \\
\hline Ethanol & 4 & 0 & 0 & 100 \\
\hline Isopropanol & 0 & 4 & 0 & 100 \\
\hline Methanol & 0 & 0 & 4 & 100 \\
\hline Total & 4 & 4 & 4 & 100 \\
\hline
\end{tabular}

Cumulative Proportion of Total Dispersion 1.000

1.000
Table S16. Analytes with $\beta-C D$ and Dye 5

Jackknifed Classification Matrix
\begin{tabular}{|l|r|r|r|r|}
\hline & Ethanol & Isopropanol & Methanol & $\%$ correct \\
\hline Ethanol & 4 & 0 & 0 & 100 \\
\hline Isopropanol & 0 & 4 & 0 & 100 \\
\hline Methanol & 0 & 0 & 4 & 100 \\
\hline Total & 4 & 4 & 4 & 100 \\
\hline
\end{tabular}

Cumulative Proportion of Total Dispersion

$$
\begin{array}{|l|r|}
0.778 & 1.000 \\
\hline
\end{array}
$$

Table S17. Analytes with Me- $\beta-\mathrm{CD}$ and Dye 5

Jackknifed Classification Matrix

\begin{tabular}{|l|r|r|r|r|}
\hline & Ethanol & Isopropanol & Methanol & \%correct \\
\hline Ethanol & 4 & 0 & 0 & 100 \\
\hline Isopropanol & 0 & 4 & 0 & 100 \\
\hline Methanol & 0 & 0 & 4 & 100 \\
\hline Total & 4 & 4 & 4 & 100 \\
\hline
\end{tabular}

Cumulative Proportion of Total Dispersion

\begin{tabular}{l|r|}
0.749 & 1.000 \\
\hline
\end{tabular}

Table S18. Analytes with 2-HP- $\beta-C D$ and Dye 5

Jackknifed Classification Matrix

\begin{tabular}{|l|r|r|r|r|}
\hline & Ethanol & Isopropanol & Methanol & \%correct \\
\hline Ethanol & 4 & 0 & 0 & 100 \\
\hline Isopropanol & 0 & 4 & 0 & 100 \\
\hline Methanol & 0 & 0 & 4 & 100 \\
\hline Total & 4 & 4 & 4 & 100 \\
\hline
\end{tabular}

Cumulative Proportion of Total Dispersion

\begin{tabular}{l|l|}
0.998 & 1.000 \\
\hline
\end{tabular}


Summary Tables for RGB Measures of Varying Concentrations of Analyte in 2-Hydroxypropyl- $\beta$ Cyclodextrin Solution with Dyes 4 and 5 Arrays

Table S19. 0.5 M Analyte solution in 2-HP- $\beta-\mathrm{CD}$ with Dye 4

Jackknifed Classification Matrix
\begin{tabular}{|l|r|r|r|r|}
\hline & B-eth & B-iso & B-meth & \%correct \\
\hline B-eth & 2 & 0 & 1 & 67 \\
\hline B-iso & 2 & 1 & 0 & 33 \\
\hline B-meth & 0 & 1 & 2 & 67 \\
\hline Total & 4 & 2 & 3 & 56 \\
\hline
\end{tabular}

Cumulative Proportion of Total Dispersion 0.849 1.000

Table S20. 1.0 M Analyte solution in 2-HP- $\beta-\mathrm{CD}$ with Dye 4

Jackknifed Classification Matrix
\begin{tabular}{|l|r|r|r|r|}
\hline & B-eth & B-iso & B-meth & $\%$ correct \\
\hline B-eth & 0 & 2 & 1 & 0 \\
\hline B-iso & 3 & 0 & 0 & 0 \\
\hline B-meth & 1 & 0 & 2 & 67 \\
\hline Total & 4 & 2 & 3 & 22 \\
\hline
\end{tabular}

Cumulative Proportion of Total Dispersion 0.906 1.000

Table S21. 2.0 M Analyte solution in 2-HP- $\beta-C D$ with Dye 4

Jackknifed Classification Matrix

\begin{tabular}{|l|r|r|r|r|}
\hline & B-eth & B-iso & B-meth & \%correct \\
\hline B-eth & 2 & 0 & 1 & 67 \\
\hline B-iso & 1 & 2 & 0 & 67 \\
\hline B-meth & 1 & 0 & 2 & 67 \\
\hline Total & 4 & 2 & 3 & 67 \\
\hline
\end{tabular}

Cumulative Proportion of Total Dispersion

\begin{tabular}{l|l|}
0.717 & 1.000 \\
\hline
\end{tabular}

Table S22. 3.0 M Analyte solution in 2-HP- $\beta-\mathrm{CD}$ with Dye 4

Jackknifed Classification Matrix
\begin{tabular}{|l|r|r|r|r|}
\hline & B-eth & B-iso & B-meth & $\%$ correct \\
\hline B-eth & 3 & 0 & 0 & 100 \\
\hline B-iso & 0 & 3 & 0 & 100 \\
\hline B-meth & 1 & 0 & 2 & 67 \\
\hline Total & 4 & 3 & 2 & 89 \\
\hline
\end{tabular}

Cumulative Proportion of Total Dispersion 0.993

1.000
Table S23. 0.5 M Analyte solution in 2-HP- $\beta-\mathrm{CD}$ with Dye 5

Jackknifed Classification Matrix
\begin{tabular}{|l|r|r|r|r|}
\hline & R-eth & R-iso & R-meth & $\%$ correct \\
\hline R-eth & 0 & 2 & 1 & 0 \\
\hline R-iso & 0 & 3 & 0 & 100 \\
\hline R-meth & 0 & 0 & 3 & 100 \\
\hline Total & 0 & 5 & 4 & 67 \\
\hline
\end{tabular}

Cumulative Proportion of Total Dispersion

\begin{tabular}{l|l|}
0.898 & 1.000 \\
\hline
\end{tabular}

Table S24. 1.0 M Analyte solution in 2-HP- $\beta-C D$ with Dye 5

Jackknifed Classification Matrix
\begin{tabular}{|l|r|r|r|r|}
\hline & R-eth & R-iso & R-meth & $\%$ correct \\
\hline R-eth & 3 & 0 & 0 & 100 \\
\hline R-iso & 0 & 3 & 0 & 100 \\
\hline R-meth & 0 & 0 & 3 & 100 \\
\hline Total & 3 & 3 & 3 & 100 \\
\hline
\end{tabular}

Cumulative Proportion of Total Dispersion 0.994 1.000

Table S25. 2.0 M Analyte solution in 2-HP- $\beta-\mathrm{CD}$ with Dye 5

Jackknifed Classification Matrix
\begin{tabular}{|l|r|r|r|r|}
\hline & R-eth & R-iso & R-meth & $\%$ correct \\
\hline R-eth & 3 & 0 & 0 & 100 \\
\hline R-iso & 0 & 3 & 0 & 100 \\
\hline R-meth & 0 & 0 & 3 & 100 \\
\hline Total & 3 & 3 & 3 & 100 \\
\hline
\end{tabular}

Cumulative Proportion of Total Dispersion

\begin{tabular}{l|l|}
0.980 & 1.000 \\
\hline
\end{tabular}

Table S26. 3.0 M Analyte solution in 2-HP- $\beta-C D$ with Dye 5

Jackknifed Classification Matrix

\begin{tabular}{|l|r|r|r|r|}
\hline & R-eth & R-iso & R-meth & \%correct \\
\hline R-eth & 1 & 2 & 0 & 33 \\
\hline R-iso & 0 & 3 & 0 & 100 \\
\hline R-meth & 0 & 0 & 3 & 100 \\
\hline Total & 1 & 5 & 3 & 78 \\
\hline
\end{tabular}

Cumulative Proportion of Total Dispersion

\begin{tabular}{ll}
0.981 & 1.000 \\
\hline
\end{tabular}




\section{SUMMARY TABLES FOR CONTROL EXPERIMENTS}

Table S27. Dye 4 in the absence of cyclodextrin:

Jackknifed Classification Matrix
\begin{tabular}{|l|r|r|r|r|}
\hline & Ethanol & Isopropanol & Methanol & \%correct \\
\hline Ethanol & 3 & 0 & 1 & 75 \\
\hline Isopropanol & 0 & 4 & 0 & 100 \\
\hline Methanol & 0 & 0 & 4 & 100 \\
\hline Total & 3 & 4 & 5 & 92 \\
\hline
\end{tabular}

Cumulative Proportion of Total Dispersion

\begin{tabular}{l|r|}
0.863 & 1.000 \\
\hline
\end{tabular}

Table S28. Dye 5 in the absence of cyclodextrin:

Jackknifed Classification Matrix

\begin{tabular}{|l|r|r|r|r|}
\hline & Ethanol & Isopropanol & Methanol & \%correct \\
\hline Ethanol & 3 & 1 & 0 & 75 \\
\hline Isopropanol & 1 & 2 & 1 & 50 \\
\hline Methanol & 0 & 0 & 4 & 100 \\
\hline Total & 4 & 3 & 5 & 75 \\
\hline
\end{tabular}

Cumulative Proportion of Total Dispersion

0.882

1.000 


\section{SUMMARY FIGURES FOR COLORIMETRIC ARRAY EXPERIMENTS}

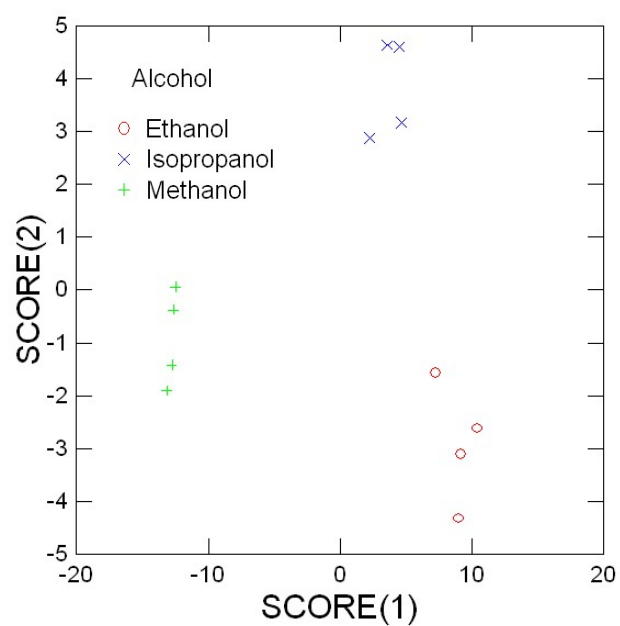

Figure S10. Analytes with $\beta-C D$ and Dye 4

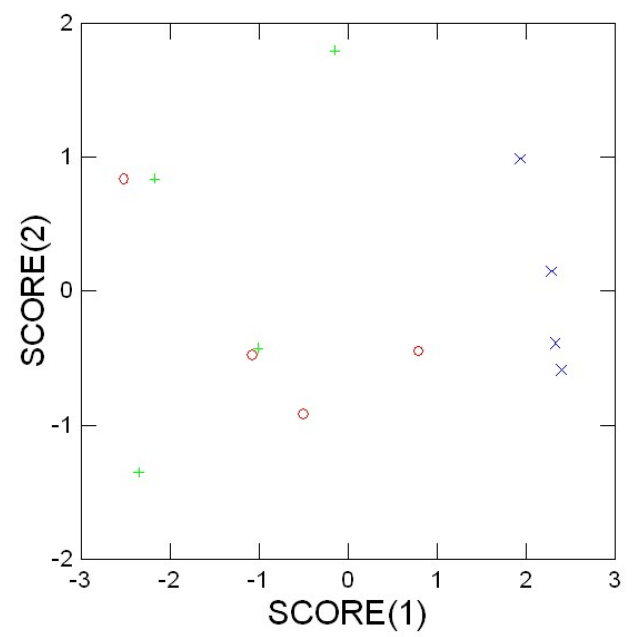

Figure S11. Analytes with Me- $\beta-C D$ and Dye 4

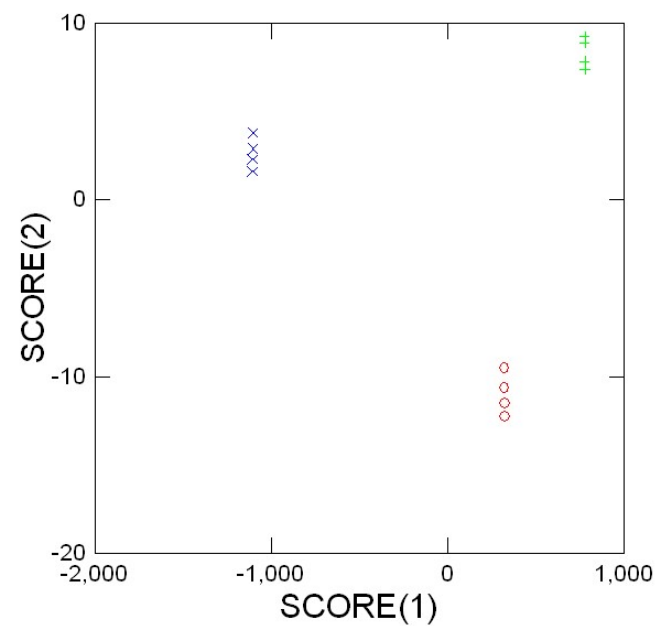

Figure S12. Analytes with $2-\mathrm{HP}-\beta-\mathrm{CD}$ and Dye 4

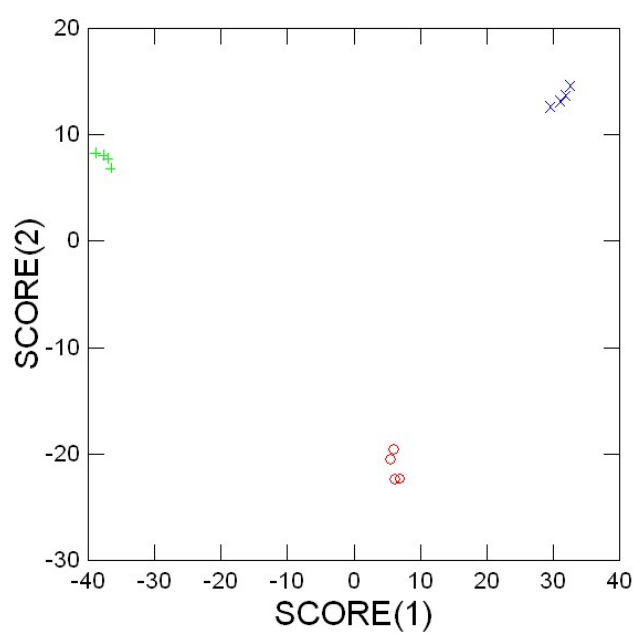

Figure S13. Analytes with $\beta-C D$ and Dye 5

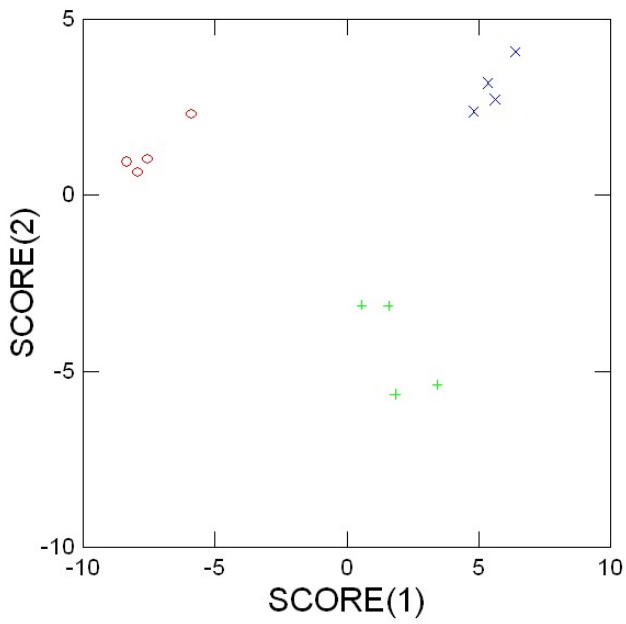

Figure S14. Analytes with Me- $\beta-\mathrm{CD}$ and Dye 5

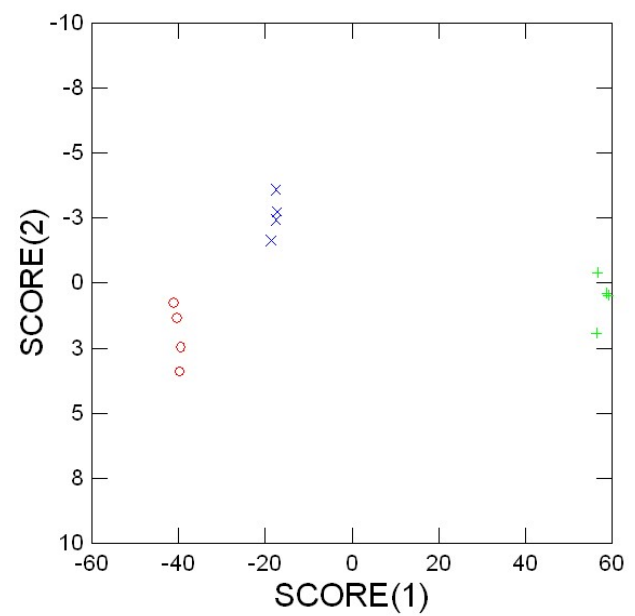

Figure S15. Analytes with 2-HP- $\beta-C D$ and Dye 5 


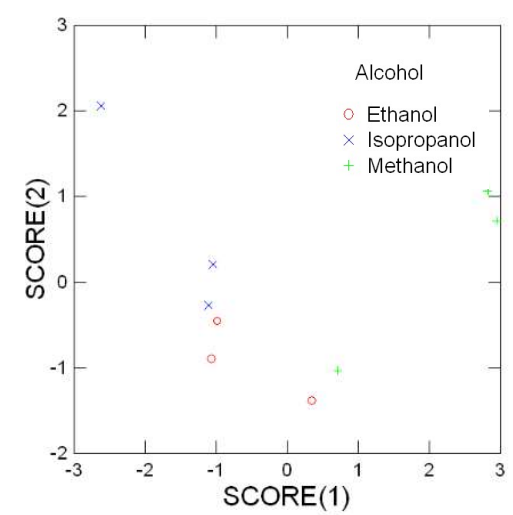

Figure S16. $0.5 \mathrm{M}$ Analytes in 2-HP- $\beta-C D$ with Dye 4

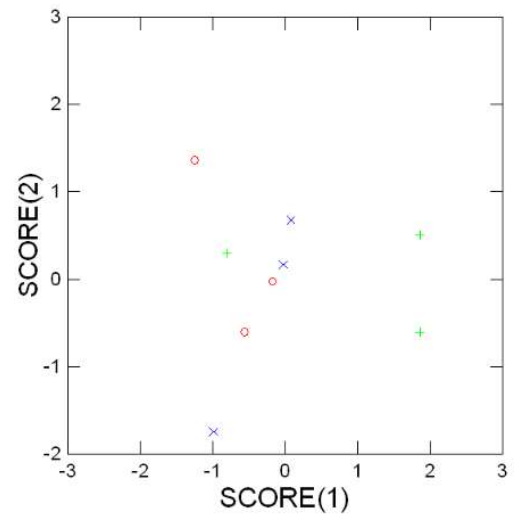

Figure S17. 1.0 M Analytes in 2-HP- $\beta$-CD with Dye 4

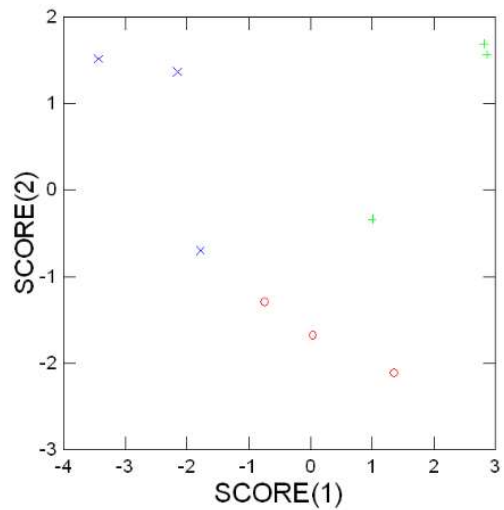

Figure S18. 2.0 M Analytes in 2-HP- $\beta-C D$ with Dye 4

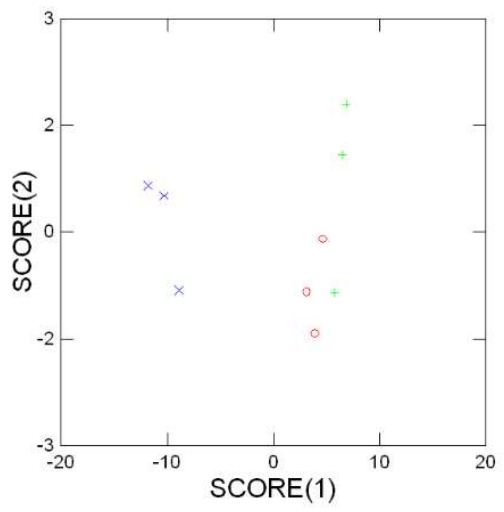

Figure S19. 3.0 M Analytes in 2-HP- $\beta-\mathrm{CD}$ with Dye 4

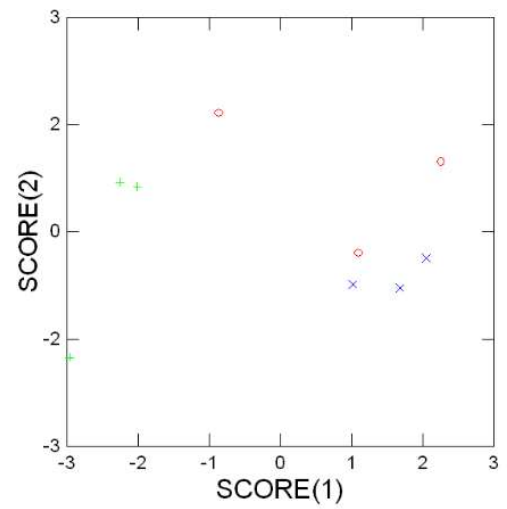

Figure S20. 0.5 M Analytes in 2-HP- $\beta-C D$ with Dye 5

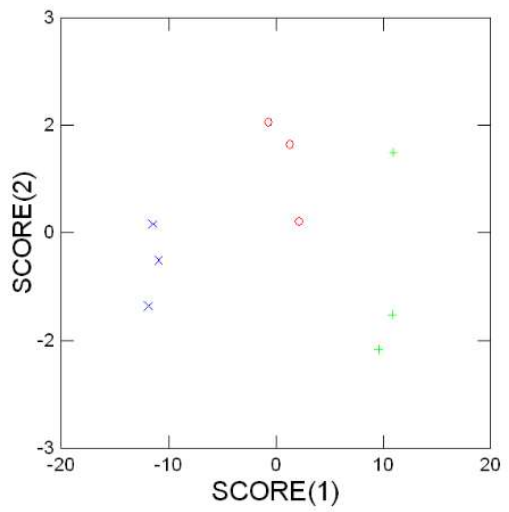

Figure S21. 1.0 M Analytes in 2-HP- $\beta$-CD with Dye 5 


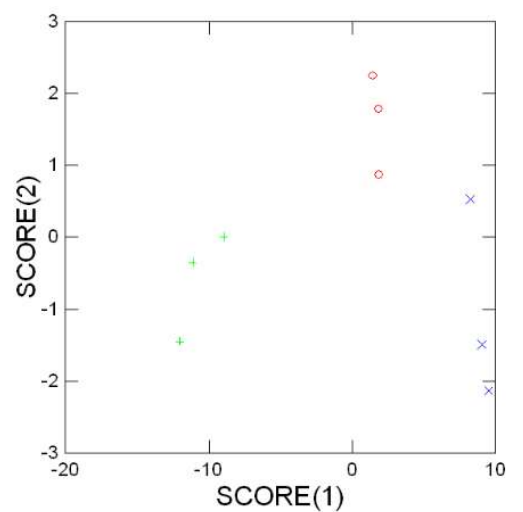

Figure S22. 2.0 M Analytes in 2-HP- $\beta-C D$ with Dye $\mathbf{5}$

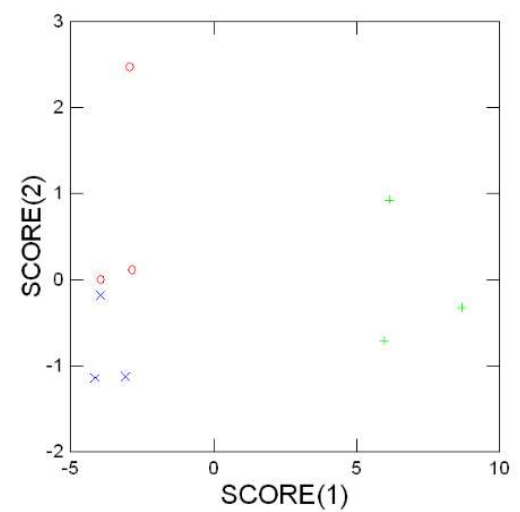

Figure 23. 3.0 M Analytes in 2-HP- $\beta-\mathrm{CD}$ with Dye 5 


\section{SUMMARY FIGURES FOR CONTROL EXPERIMENTS}

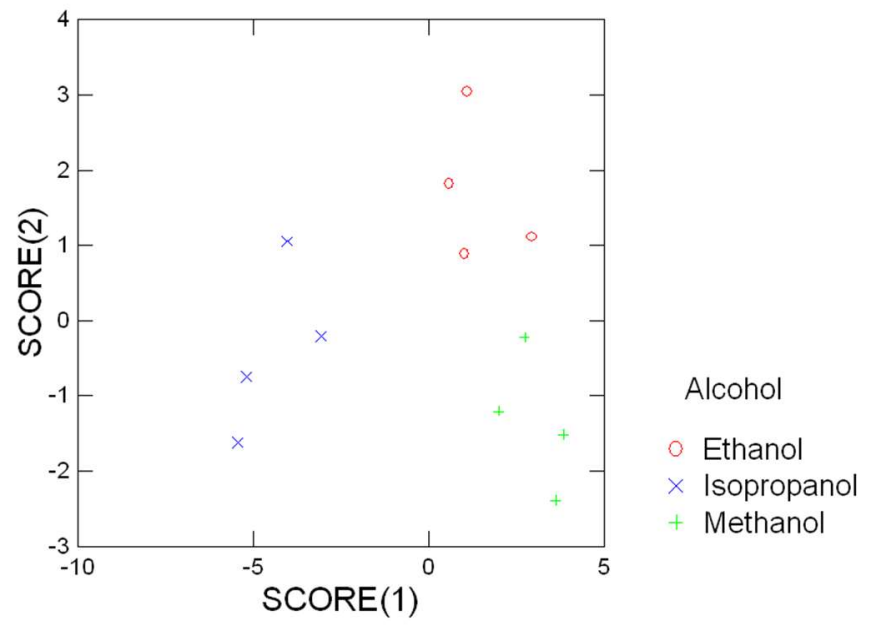

Figure S24. Dye 4 in the absence of cyclodextrin

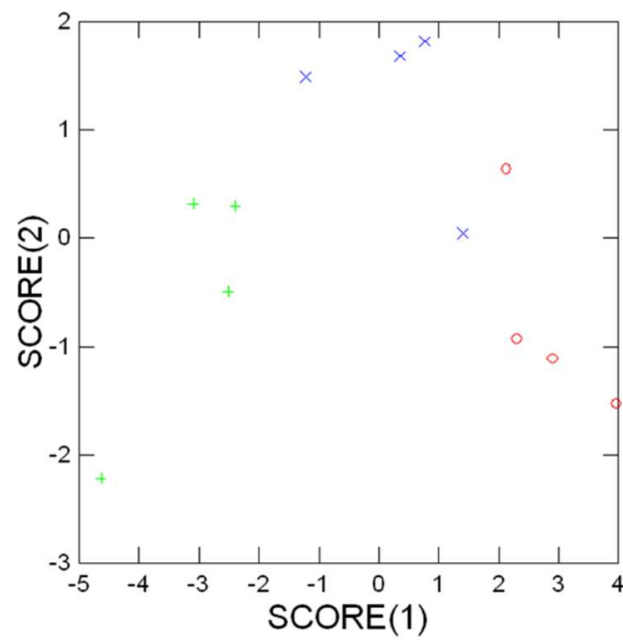

Alcohol

- Ethanol

$\times$ Isopropanol

+ Methanol

Figure S25. Dye 5 in the absence of cyclodextrin 


\section{SUMMARY FIGURES FOR ALL LOD EXPERIMENTS}

The red lines shown on each graph are representative of the lines of best fit of the equations given on page S18 in Table S9.

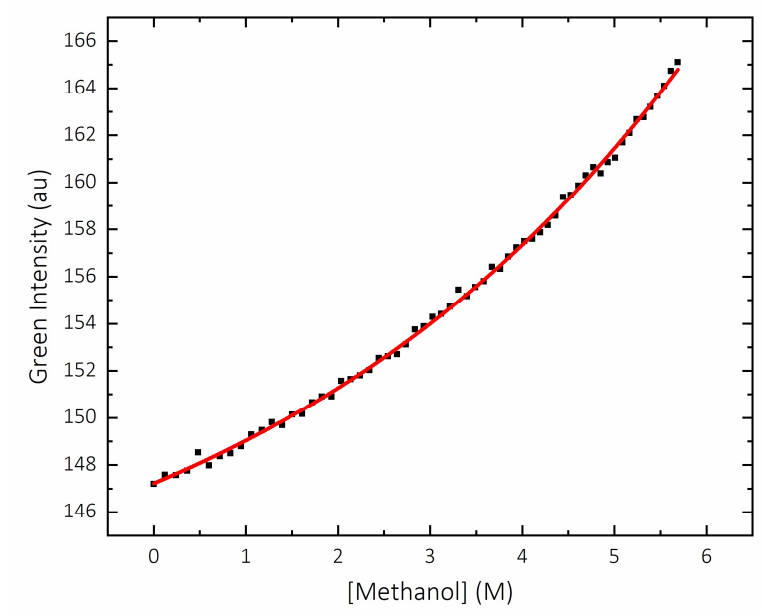

Figure S26. Limit of Detection Results for Analyte 1 - Dye 4

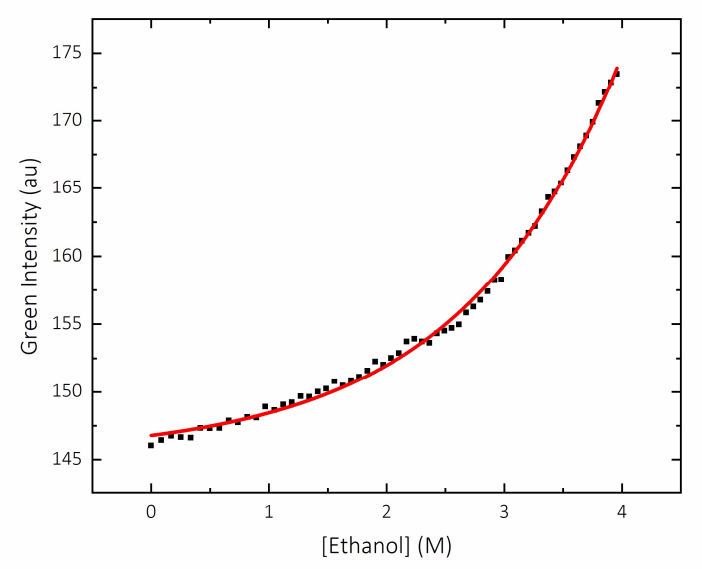

Figure S27. Limit of Detection Results for Analyte 2 - Dye 4

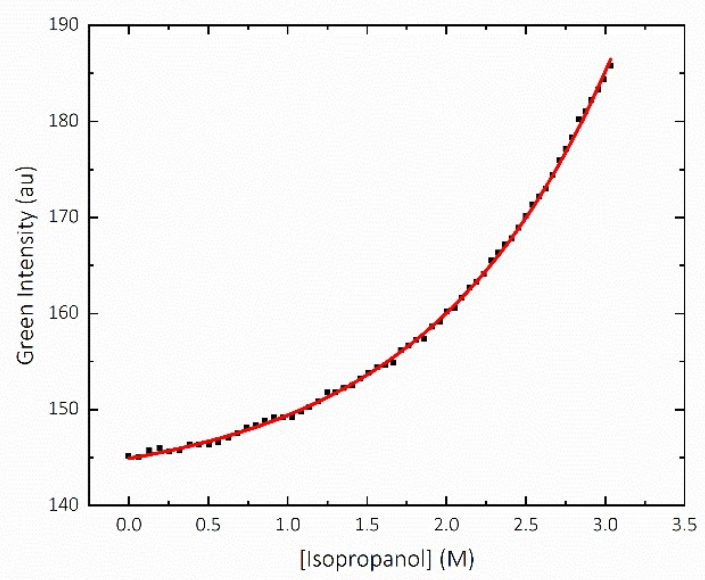

Figure S28. Limit of Detection Results for Analyte 3 - Dye 4 


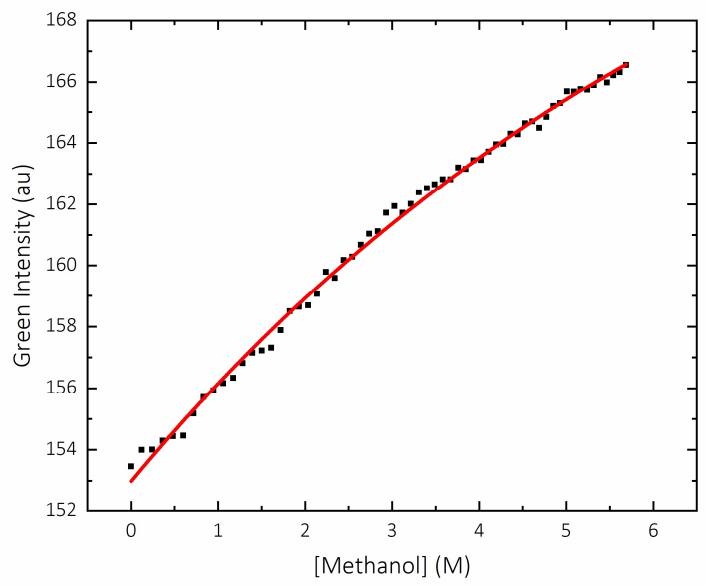

Figure S29. Analyte 1 - Dye 5

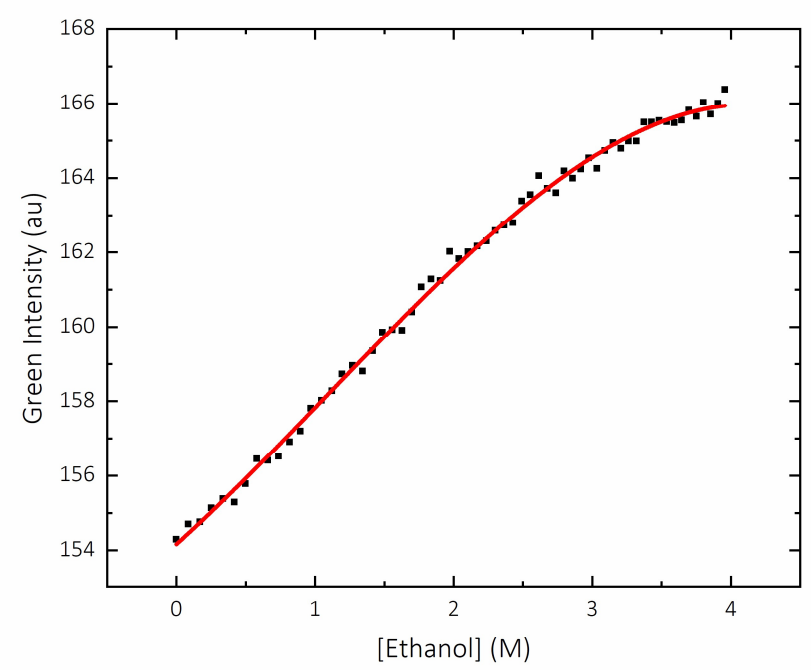

Figure S30. Analyte 2 - Dye 5

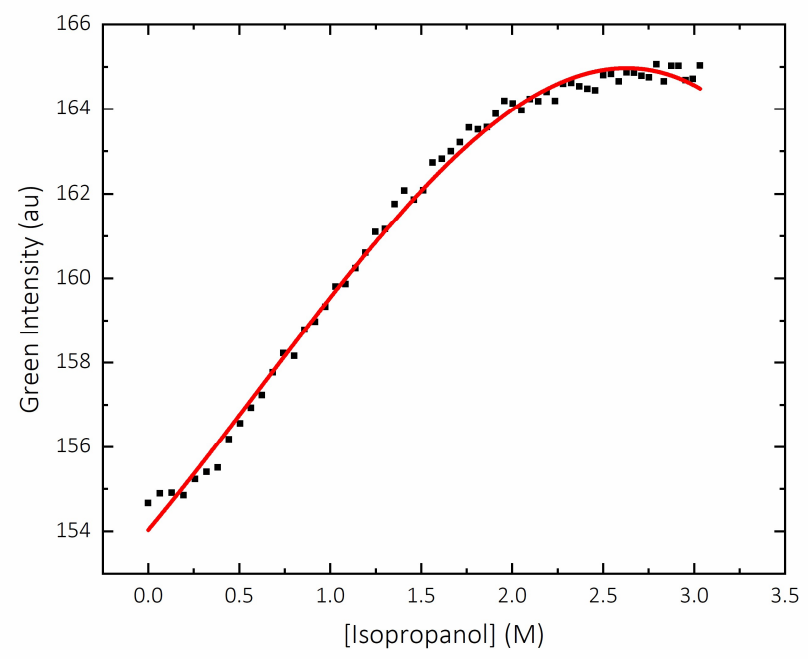

Figure S31. Analyte 3 - Dye 5 


\section{REFERENCES}

(1) Loock, H.-P.; Wentzell, P. D. Detection Limits of Chemical Sensors: Applications and Misapplications. Sensors and Actuators B: Chemical 2012, 173, 157-163. https://doi.org/10.1016/j.snb.2012.06.071.

(2) Belter, M.; Sajnóg, A.; Barałkiewicz, D. Over a Century of Detection and Quantification Capabilities in Analytical Chemistry - Historical Overview and Trends. Talanta 2014, 129, 606-616. https://doi.org/10.1016/j.talanta.2014.05.018. 
